\title{
Determinants of Gender Differences on Soybean Production in Bambasi District, Benishangul Gumuz National Regional State, Ethiopia
}

\author{
Hawa Mehari $^{1}$ Mulu Debela ${ }^{2} \quad$ HabtamuAshagre $^{3 *}$ \\ 1.Assosa Agricultural Research Center, Ethiopian Institute of Agricultural Research, P.O.Box 265, Ethiopia \\ 2.School of Agricultural Extension and Rural Development, Department of Development studies, Ambo \\ University, Ethiopia \\ 3.College of Agriculture and Veterinary Science, Department of Plant Sciences, Ambo University, Ethiopia
}

\begin{abstract}
The study was undertaken to examine the determinants of gender difference in soybean production among male and female headed soybean producer households at Bambasi District, Benishangul Gumuz Regional State, Ethiopia. Multi stage, sampling procedure was used to select sample respondents. In the district, ten kebeles were selected purposively according to the intensity of soybean production. Out of ten kebeles, five kebeles were selected by simple random sampling technique. Based on the list of the beneficiaries, households were selected using probabilities proportional to sample size procedure. A total of 136 households of soybean producer farmers (78 Male headed household (MHH) and 58 Female headed household (FHH)) were selected; and data was collected using semi structured questionnaire, interview and focus group discussion. Descriptive statistics, Ordinary Least Square Regression were used for the analysis of the data. The analysis of the data showed that $34.62 \%$ male headed and $67.24 \%$ female headed households were illiterate. The average land owned by MHH and FHH was 2.28 ha and 1.83 ha respectively, and the total of $58.97 \% \mathrm{MHH}$ and $32.76 \% \mathrm{FHH}$ had got credit service. As far as input utilization the majority of the respondents $(56.41,75.64 \% \mathrm{MHH}$ and $72.41,82.76 \%$ FHH) did not used fertilizer and pesticides, respectively. OLS estimation revealed that education of household head, household labour force, cultivated land size, tropical livestock unit, access to credit, frequency of extension contact, fertilizer application, hired labour, membership in social organization significantly affected the production of soybean in both men and female headed households; while pesticide application significantly affected MHH only. The study revealed men headed households have got higher production of soybean by utilizing the accessible input than FHH. Hence, similarly FHH should be encouraged and supported to access inputs for improving soybean productivity, and to increase the level of food security in the area.
\end{abstract}

Keywords: Determinants, Gender difference, Soybean production

DOI: $10.7176 / \mathrm{JAAS} / 55-01$

Publication date:May $31^{\text {st }} 2019$

\section{Introduction}

Soybean (Glycine max L.) is one of the most important leguminous and oil crop with worldwide growing importance; as food and market commodity. The importance of soybean emanates from the high nutritional value of its grain (Gurumu et al., 2009). Soybean is grown in different parts of Ethiopia; the major areas currently growing the crop are situated in the western and south-western part of the country, notably Benishangul-Gumuz, Gambela and parts of Oromia Region. Oromia and Benishangul-Gumuz regions account for the highest production of soybean in the country, 51\% and $40 \%$ respectively (Sopov and Yared., 2015), its national average yield is $2.05 \mathrm{t} \mathrm{ha}^{-1}$ which is below the global average (CSA, 2015).

There are several reasons to promote soybean on small scale farmer's field of developing countries. For instance in Ethiopia, most people cannot consistently eat these protein-rich foods (meat, poultry, eggs and milk) because they simply lie outside their economic grasp. In addition, because of religious reasons, a little more than 40 percent of the country's 100 million people forgo eating livestock products more than 250 days out of the year (USDA, 2016). All this adds up to a protein-deficient diet for many Ethiopians, which is one of the factors behind the nation's high rates of malnutrition, especially among women and children. Moreover, Ethiopia imports large quantities of soybean, sunflower and palm oil. The value of imported edible oil is 40 to $50 \%$ of the export earnings of oilseeds (Eneyew, 2013). Oilseed crushers produce around $20 \%$ of the domestic consumption of edible oil, and $80 \%$ is imported mainly as palm oil and soybean oil (Fanta et al., 2011). However, opportunities exist to substitute imported soybean and sunflower oil. Increased domestic edible oil production can substitute these imports and improve the trade balance (Wijnands et al., 2009). In addition to edible oil, a significant amount of soya blend food is imported to Ethiopia; implying a further potential for import substitution.

Gender difference in crop production has major effect on production and productivity of soybean. Men and women own key productive resources and agricultural inputs which are considerably varied. Soybean production 
is affected by input and variable technologies. Women face numerous obstacles to access productive inputs and assets; however their contribution in soybean production to support the national economy is imperative. The communities of Bambasi district are traditionally an agrarian; however the effect of gender roles in soybean production in such communities has hardly been addressed. Therefore, this study seeks to explore the determinants of gender differences on soybean production in the study area.

\section{Research Methodology}

Description of study area

Bambasi district is among the seven districts found in Assosa zone of Benishangul Gumuz National Regional States. It is located at a distance of $625 \mathrm{Km}$ from Addis Ababa (Fig 1). Annual rain fall ranges from 1350-1450 $\mathrm{ml}$, and it has an average temperature of $28{ }^{\circ} \mathrm{C}$. The district has $85 \%$ lowland and $15 \%$ highland agro ecology zones. Maize, Sorghum, Soybean, Finger millet, Niger and haricot bean are the major crop grown in district. Livestock reared by most of the people include Cattle, Sheep, Goat, Donkey, Mule and Poultry (BDAO, 2016).

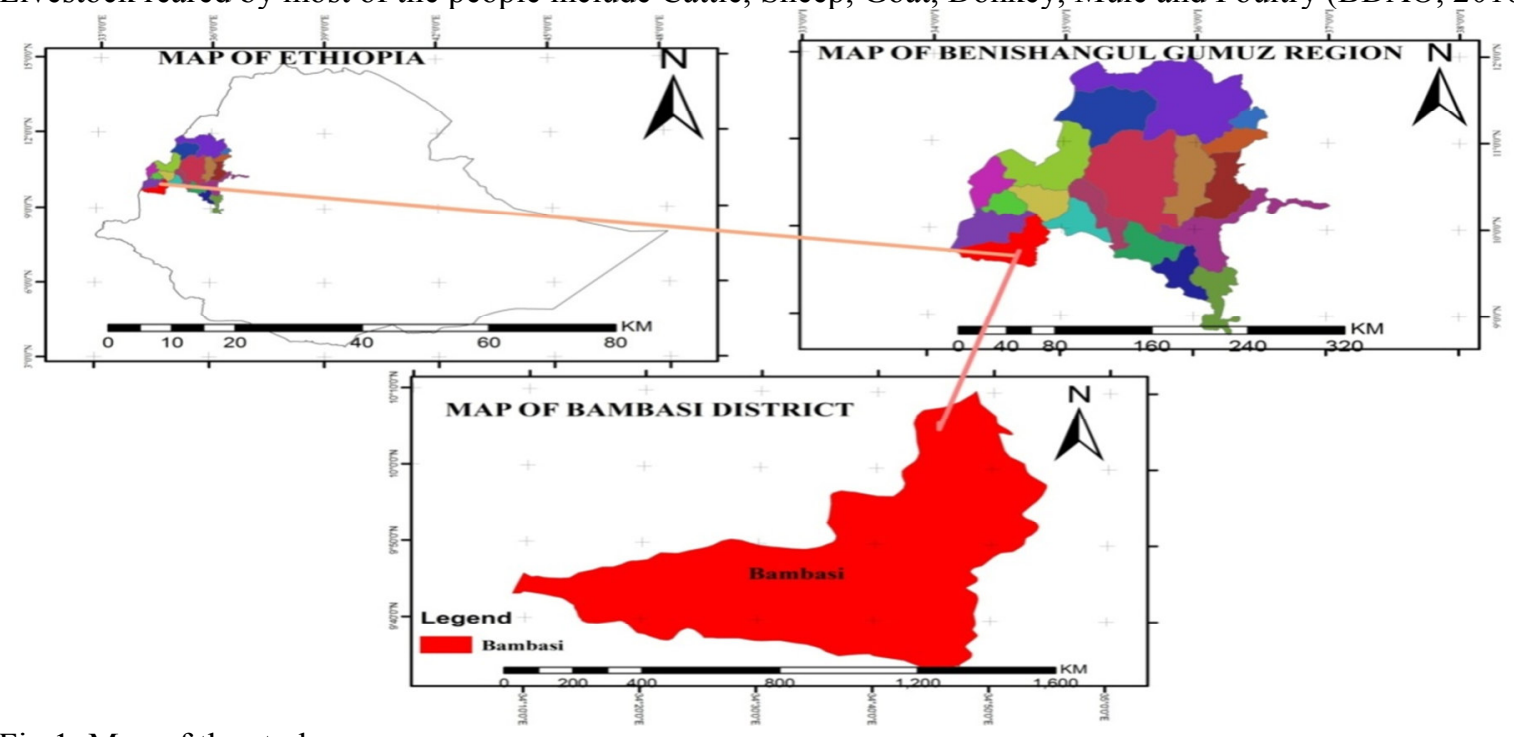

Fig 1. Map of the study area

\section{Sample design and sample technique}

A multi stage sampling procedure was employed to select sample households. Purposive sampling was used to select Bambasi district. In the district ten kebeles were selected purposively according to the intensity of soybean cultivation within the same agro ecology. Out of ten kebeles five kebeles were selected using simple random sampling techniques. Finally according to the list of household obtained from each kebele 78 MHHs were selected based on probability proportional to sample size procedure. Due to the small number of FHHs, to make adequate representation of the sample seventy percent $(70 \%)$ of the sample size was taken into account; accordingly 58 FHHs were taken for the purpose of comparison (Table 1). Based on Yamane's (1967) formula at $95 \%$ confidence level and $8 \%$ precision level a total of 136 households were selected by simple random sampling techniques.

$$
\mathrm{n}=\frac{\mathrm{N}}{1+\mathrm{N}\left(\mathrm{e}^{2}\right)}
$$

Where $\boldsymbol{n}$ is sample size, $\boldsymbol{N}$ is population size, $\boldsymbol{e}$ is level of precision.

Table 1: Distribution of sample households

\begin{tabular}{lllllll}
\hline & \multicolumn{2}{c}{ Number of households } & \multicolumn{3}{c}{ Number of respondents } \\
\hline Study kebele & Total & MHH & FHH & Total & MHH & FHH \\
Mender 46 & 233 & 215 & 18 & 31 & 18 & 13 \\
Mender 49 & 224 & 214 & 10 & 25 & 18 & 7 \\
Nebar Keshmando & 256 & 235 & 21 & 35 & 20 & 15 \\
Sonka & 142 & 130 & 12 & 19 & 11 & 8 \\
Dabus & 144 & 123 & 21 & 26 & 11 & 15 \\
Total & 999 & 917 & 82 & 136 & 78 & 58 \\
\hline
\end{tabular}

Data collection and analysis

Both primary and secondary data were used for the study. Primary data were collected from the target 
respondents with the aid of questioner, interview and focus group discussion. Both qualitative and quantitative data were analyzed using STATA13 Software. Descriptive statistics like mean, frequency, percentage, t-test and chi-square $\left(x^{2}\right)$ tests were used for categorical and continuous variable. Ordinary Least-Square Regression (OLS) was used to identify determinants of gender difference in soybean production.

\section{Model specification for Ordinary Least-Squares (OLS) Regression}

OLS regression is particularly powerful as it relatively easy also check the model assumption such as linearity; constant variance and the effect of outliers using simple graphical methods (Hutcheson and Moutinho, 2008). The OLS regression model includes multiple explanatory variables by simply adding variables to the equation.

$\mathrm{Y}=\alpha+\beta_{1} x_{1}+\beta_{2} x_{2}+\beta_{3} x_{3}+\cdots \cdots \cdots \beta_{x} x_{n}$

Where $\mathrm{Y}=$ soybean output measured in quintal, $\mathrm{x}_{1}, \mathrm{x}_{2}, \mathrm{x}_{3} \ldots . \mathrm{x}_{\mathrm{n}}$ refers to all explanatory variable used in the model, $\alpha$ indicates the value of $y$ when all explanatory variables are Zero. Each $\beta$ Parameter refers to the average change in soybean output $(\mathrm{Y})$ that is associated in with unit change in explanatory variable $(\mathrm{x})$, while controlling the other for the explanatory variable in the model.

\section{Multi- co linearity test}

Multi-co linearity test among continuous variable and degree of association among discrete variable is important before running the analysis to identify whether there is Multi co linearity association or not. The reason for this test was, serious multi-co linearity among the variable will affects the estimates seriously. Following Gujirati (2004), Variance Inflation Factor (VIF) is used to test the existence of Multi- co linearity among the continuous variable and Tolerance level (TOL) where each continuous explanatory variable is regressed on all the other continuous explanatory variables and coefficient of determination is computed. Contingency coefficient is used to check the association among the discrete explanatory variable.

The measure of multi co linearity among the continuous variable defined by VIF is indicated as:

$\operatorname{VIF}\left(x_{i}\right)=\left(1-R^{2}\right)^{-1}$

Where, $R^{2}$ is the coefficient of determination when the variable, $x_{i}$ is regressed on the others Explanatory variables.

$\operatorname{TOL}\left(x_{i}\right)=\left(1-R^{2}\right)$

TOL $\mathrm{i}=$ Tolerance level of $\mathrm{i}$ explanatory variable

$R^{2}=$ Coefficient of determination of $\mathrm{i}$ explanatory variable

The larger the value of VIF the more taxing is the multi co linearity of variable $\left(x_{i}\right)$. If the VIF of a variable exceeds 10 (this will happen if $R^{2}$ exceeds 0.90 ) that Variable is said to be highly collinear. Similarly, TOL approaches to one when the variable $\left(x_{i}\right)$ is not correlated with other variables. Accordingly the VIF of continuous explanatory were computed and the result was small (VIF is less than 10) indicating that there were no strong multi co linearity problem among the variables. Similarly the contingency coefficient of discrete variable was computed it takes the value less than 0.75 indicates there were no strong associations among the variable

\section{Result and Discussion}

Descriptive statistics

Level of Education: According to the survey a total of 78 (34.62\%) male headed and $58(67.24 \%)$ female headed households were illiterate (Table 2). The proportion of male headed who read and write was $16.67 \%$, while FHH was $12.07 \%$. In the same survey the proportion of male headed who attended grade $1-4$ was $17.95 \%$ while that of female headed household was $12.07 \%$. The rest 16.67 and $11.54 \%$ of male headed, and 6.90 and $1.72 \%$ of female headed households attend grade 5-8 and 9-10, respectively. The remaining $2.56 \%$ attended grade 11-12 for male headed household. Unfortunately none of female headed household attended this grade. The result shows it was statistically significant at less than $1 \%$ probability level $\left(\chi^{2}=16.9, \mathrm{p}=0.005\right)$. The result was agreed with Asres et al., (2015) on their case study in northwest Ethiopia, who found that FHH were on average less educated than $\mathrm{MHH}$.

Table 2. Educational level of the household head in percent

\begin{tabular}{lllll}
\hline Illiteracy & MHH(78) & FHH(58) & All cases(136) & $\chi^{2}$-test \\
\hline Illiterate & 34.6 & 67.24 & 50.93 & \\
Read and write & 16.67 & 12.07 & 14.37 & $\chi^{2}=16.90^{* * *}$ \\
Grade 1-4 & 17.97 & 12.07 & 15.00 & $\mathrm{P}=0.005$ \\
Grade 5-8 & 16.67 & 6.9 & 11.79 & \\
Grade 9 and 10 & 11.54 & 1.72 & 6.63 & \\
Grade 11 and12 & 2.56 & 0.00 & 1.28 & \\
\hline
\end{tabular}

Source: Own survey 
Household labour force: According to the study, the mean family size in Adult equivalent (AE) were 4.60 and 3.15 in male headed and female headed households, respectively, which was statistically different $t=5.3$, $\mathrm{p}=0.0000$. Similarly Asres et al., (2015) reported that FHH had lower family size compared to MHH in North West Ethiopia.

Land Holding: The total area of land that was under different rights owned by the sample households was about 284.77 ha with average of 2.093 ha per household. The average land owned by MHH and FHH was 2.28 ha and 1.83 ha respectively, which is statistically significant at less than $5 \%$ probability level $(t=1.77, p=0.0393)$. The finding is consistent with that of Tadele and Mahendran (2015) in their study of gender differences showed that land holding of FHH was smaller than that of $\mathrm{MHH}$.

Livestock holding: The average livestock owned by sample farmers was 3.39 Total Livestock Unit (TLU). The mean livestock size owned by $\mathrm{MHH}$ and FHH indicate that, MHH has 4.29 TLU and FHH has also 2.16 TLU which was significantly different at $1 \%$ probability level $(\mathrm{t}=3.57)$. This indicates that $\mathrm{MHH}$ has larger livestock unit than FHH. This result is similar with Muyanga et al., (2011) in Kenya; Tegebu et al., (2012); Tadele and Mahendran (2015), and Bethelhem (2016) in Ethiopia.

Access to credit service: The survey result indicated that from the total of $78 \mathrm{MHH}$ and $58 \mathrm{FHH}, 58.97 \%$ and $32.76 \%$ had got credit service and the rest of $41.03 \%$ of $\mathrm{MHH}$ and $67.24 \%$ of FHH had no got credit service, respectively. The chi square test indicated that it was significantly different at less than $1 \%$ probability level $(\chi 2$ 9.1625). This indicates that MHH were benefited more than FHH. The service providers were biased to $\mathrm{MHH}$ households, even when the FHH were having ability to bear risks; they have no collateral to gain the service. The kind of credit service given was in cash and it was varied along with the households. The amount of credit on average received was 1917.95 birr in $\mathrm{MHH}$ and 843.10 birr in FHH. The t- test result indicates that the amount of credit in cash received was significantly different at less than $1 \%$ probability level. The finding was in agreement with the finding of Davis et al., (2010) in Ethiopia, farmers' access to agricultural credit and financial services remains inadequate, particularly female heads frequently lack credit, which make it difficult for them to obtain inputs (Tewodaj et al., 2009).

Frequency of extension contact: The frequency of extension contact among sample households was varying in $\mathrm{MHH}$ and $\mathrm{FHH}$. The survey result indicates that the frequency of extension contact was significantly different in both $\mathrm{MHH}$ and $\mathrm{FHH}$ at less than $1 \%$ probability level $(\mathrm{t}=2.4076)$. This result was consistent with Doss et al., (2003) findings in the meta-analysis of 22 case studies in Africa found that lack of access to agricultural extension is the major constraint faced by farmers, especially women farmers, which limit their uptake of technological innovations. For those who have access, the quality of service and the appropriateness of information are often cited as issues.

Fertilizer use: According to the study, $43.59 \%$ of $\mathrm{MHH}$ and $27.59 \%$ of $\mathrm{FHH}$ applied fertilizer during the main cropping season. The majority of the respondents $(56.41 \%$ of $\mathrm{MHH}$ and $72.41 \% \mathrm{FHH})$ responded that there was no application of fertilizer in the same cropping season. The chi- square test shows that it was significantly deferent at less than $10 \%$ probability level $\left(\chi^{2}=3.6646\right)$. The result was consistent with findings of Tadele and Mahendran , (2015) on the study conducted in SNNP of Ethiopia.

Hired labour: People in the study area help each other by means of exchange labour (Wonfel) and labour pooling mechanism (Debo). Wonfel was the most used practices which the household is served in reciprocal to one another. The other labour arrangement was Debo, which the household is request their neighbor or relative without an arrangement to perform their activities in return. Hired labour was used when the household is in need of more labour in addition to exchange labour and labour pooling mechanism. MHH hire more labour than $\mathrm{FHH}$ and the chi square test indicate that it was significantly different at less than $10 \%$ probability level $(p=0.054)$. The results of this study is in agreement with Bethelhem and Holden (2008) who found significant difference among $\mathrm{MH}$ and $\mathrm{FH}$ households in terms of hiring labour for farm activities.

Membership in social organization: The survey result indicated that $71.79 \%$ of $\mathrm{MHH}$ and $46.55 \%$ of FHHs were membership in social organization, while the remaining $28.21 \%$ and $53.45 \%$ of $\mathrm{MHH}$ and FHHs were not involved, respectively. The chi-square test indicated that there was a significant difference at less than $1 \%$ probability level. This indicated that FHHs were not treated equally as MHH, even when FHH were active the service given was biased to MHH. Gotschi, and Delve (2008) on Mozambique suggests the presence of considerable gender differences in participation in membership and leadership in mixed-group cooperatives, associations and organizations, and women being less likely to participate and hold management positions.

Pesticide use: The result of the survey indicated that $24.36 \%$ of $\mathrm{MHH}$ and $17.24 \%$ of $\mathrm{FHH}$ were pesticide users, while the majority of the respondents were reported that they were non-users. The chi- square test indicates there was no significant difference among the households $(\chi 2=1.004, \mathrm{p}=0.316)$. The result is similar with finding of Tadele and Mahendran (2015) on the study conducted in SNNP of Ethiopia.

\section{Econometric Results}

The OLS estimate and determinants soybean production discussed below and illustrated on Table 3. 
Education of the household head: It was positive and had significant impact at less than $5 \%$ and $1 \%$ probability level in both $\mathrm{MHH}$ and $\mathrm{FHH}$, respectively (Table 3). As the education of the farmer increases, the ability of retrieving, accessing and interpreting the information received in a better manner. As indicated in the result an increase in one years of schooling in both $\mathrm{MHH}$ and $\mathrm{FHH}$ increase the output of soybean production by 0.215 in $\mathrm{MHH}$ and 0.607 in $\mathrm{FHH}$, respectively.

Household labour force: The availability of labour is the determinant factor in both Households. It is oblivious that, as household labour force increases the productivity of soybean in the household increases. From the result of the study, household labour force was positive and significant at less than 5\% probability level and at less than $1 \%$ probability level for $\mathrm{MH}$ and $\mathrm{FH}$ households, respectively. The other factor being constant the increment in one unit of adult equivalent increases soybean output by 0.331 and 0.964 in both $\mathrm{MH}$ and FH households, respectively. The finding of Udry et al., (1995) in Burkina Faso indicated that labor is an important factor in determining the output. Also the findings of Addis et al., (2001) confirmed that family labor had a significant and positive impact on the gross value of output for both MHHs and FHHs in Ada, Lume, and Gimbichu districts of the central highlands of Ethiopia.

Cultivated land size: Cultivated land size was positive and significant at $1 \%$ probability level for both male headed and female headed households indicating that the larger cultivating land size, increase an output of soybean production in both households. Other factor being constant increment in one unit of cultivating land size, increase the unit of soybean production output by 0.979 in $\mathrm{MHH}$ and 0.704 in $\mathrm{FHH}$. This finding is supported by Regasa et al., (2012) who reported that land size had a positive and significant impact on the gross value of output for MHHs and FHHs.

Number of livestock owned: Possession of livestock has implication on soybean production. Having livestock mean it is possible to plough the land and also allow the households to generate income through the sale of animals and their products. The result of the model indicates it was significant and positive impact for both $\mathrm{MHH}$ and $\mathrm{FHH}$ at less than 5\% probability level. An increase in one unit of TLU would increase the production of soybean output by 0.123 in $\mathrm{MHH}$ and 0.404 in FHH, respectively, keeping other factors constant. This finding agrees with the report of Addis et al., (2001).

Access to credit: The result of the survey indicate that access to credit service was significant and positive in both $\mathrm{MHH}$ and $\mathrm{FHH}$ at less than $10 \%$ probability level, respectively. The model result showed that a unit increase in household credit would increase the probability of soybean production output by 0.927 and 0.497 in both $\mathrm{MHH}$ and $\mathrm{FHH}$, respectively. This finding was supported by the findings of Villabon (2012).

Frequency of extension contact: The result emphasis that there was significant and positive influence on both $\mathrm{MHH}$ and $\mathrm{FHH}$ at less than $5 \%$ and $1 \%$ probability level, respectively. Increment in one day of extension contact, increase the production of soybean output by 0.078 and 0.473 in $\mathrm{MHH}$ and $\mathrm{FHH}$, respectively being other factors constant. This finding was supported by Yu et al., (2011) in their studies of cereal production and technology.

Fertilizer use: Application of fertilizer was significantly and positively affects both $\mathrm{MHH}$ and FHH at less than $10 \%$ and $1 \%$ level of significance, respectively. The yield of soybean production increases by 0.853 for $\mathrm{MHH}$ and 0.206 for FHH when the households were utilized fertilizer, respectively. Findings of Okpolu and Victor (2015) indicate that fertilizer use is the important factor affecting the productivity level of male and female soybean farmers in Nigeria.

Hired labour: The result showed that hired labour was significant and positive for $\mathrm{MHH}$ and $\mathrm{FHH}$ at less than 5\% and less than $1 \%$ probability level, respectively. The other factor being constant increase in one unit of hired labour increase the production of soybean output by 0.605 and 0.109 in male headed and female headed households, respectively.

Membership to social organization: membership to social organization had positive and significant effect on the output of both $\mathrm{MHH}$ and $\mathrm{FHH}$ soybean farmers at less than $10 \%$ and $5 \%$ probability level, respectively. Keeping other factors constant, membership to organization increases soybean production output by 0.161 and 0.464 For MHH and FHH, respectively.

Pesticide use: pesticide application has significant and positive effect on $\mathrm{MHH}$ at less than $10 \%$ probability level and it was insignificant for FHH. The result indicated that the yield of soybean production increases by 0.049 for MHH when the household were utilized pesticide accordingly. But the result in FHH shows that pesticide was under-utilized by the female soybean farmers. The studied conducted by Regasa et al., (2012) indicate plot level productivity differences are statistically significantly explained by the intensity of use of modern inputs such as pesticide. 
Table 3: OLS estimate result on determinants of gender difference on soybean production

\begin{tabular}{|c|c|c|c|c|c|c|}
\hline & \multicolumn{3}{|c|}{ Male headed household } & \multicolumn{3}{|c|}{ Female headed household } \\
\hline Variables & Coefficient & $\mathbf{t}$ & p-value & Coefficient & $\mathbf{t}$ & p-value \\
\hline EDUC & 0.216 & $2.23^{* *}$ & 0.029 & 0.608 & $3.1^{* * *}$ & 0.003 \\
\hline HHLF & 0.331 & $2.36^{* *}$ & 0.021 & 0.964 & $3.3^{* * *}$ & 0.002 \\
\hline CLLS & 0.979 & $20.38^{* * *}$ & 0.00 & 0.704 & $6.9^{* * *}$ & 0.00 \\
\hline TLU & 0.123 & $2.1^{* *}$ & 0.039 & 0.404 & $2.54^{* *}$ & 0.014 \\
\hline CREDIT & 0.927 & $1.75^{*}$ & 0.085 & 0.497 & $1.76^{*}$ & 0.084 \\
\hline EXC & 0.078 & $2.02^{* *}$ & 0.048 & 0.473 & $4.92^{* * *}$ & 0.00 \\
\hline FERT & 0.853 & $1.73^{*}$ & 0.088 & 0.206 & $4.06^{* * *}$ & 0.00 \\
\hline SO & 0.161 & $1.81^{*}$ & 0.074 & 0.464 & $2.06^{* *}$ & 0.045 \\
\hline HIREDL & 0.605 & $2.03^{* *}$ & 0.046 & 0.109 & $3.52^{* * *}$ & 0.001 \\
\hline PEST & 0.049 & $1.83^{*}$ & 0.071 & 0.102 & 0.1 & 0.921 \\
\hline
\end{tabular}

Source: Own computation; $\mathrm{NB}: * * *, * * *=$ Significant at $1 \%, 5 \%$ and $10 \%$ probability level

\section{Conclusion and Recommendation}

The study confirmed the existence of gender disparities between $\mathrm{MHH}$ and $\mathrm{FHH}$ in terms of access to land, labour, credit, frequency of extension contact, access to fertilizer and pesticide, livestock ownership, level of education, and membership in social organization. Thus MHH were more benefited than FHH households to undertake agricultural activities, and to boost their production and productivity. Hence, focus should also be given to the disadvantaged group of the society (women) to increase soybean production and productivity in the district. Moreover, eleven variables affect the production of soybean per hectare. Education of the household head, household labour force, hired labour, cultivated land size, number of livestock owned, credit received, frequency of extension contact, fertilizer use, and membership to social organization are determinants in soybean production for $\mathrm{MHH}$ and $\mathrm{FHH}$ households except pesticide use which was significant for MHH. Hence, improving these variables can increase soybean productivity and production in the district. Moreover, men headed households have got higher production of soybean by utilizing the accessible input level than FHH. Similarly, FHH should be encouraged and supported access inputs to improve soybean productivity, and increase the level of food security in the area.

\section{References}

Addis T., Teklu T., Mwangi, W. and, Verkuijl, H.2001.Gender differentials in agricultural production and decision-making among smallholders in Ada, Lume, and Gimbichu Woredas of the Central Highlands of Ethiopia. Mexico, D.F.: International Maize and Wheat Improvement Center (CIMMYT) and Ethiopian Agricultural Research Organization (EARO).

Asres Elias, Nohmi, M., yasunobu,K., and Ishida, A. 2015. Does Gender Division of Labour Matters for the Differences in Acccess to Agricultural Extension Services? A cases study in North West Ethiopia. Journal of Agricultural Sciences, 7(1):1-10.

Bambasi Aistrict agricultural Office (BDAO), 2016. Annual Report. PP.1-6

Bethelehem, Legese. 2016. Factors affecting differences in livestock asset ownership between male and femaleheaded households in northern Ethiopia. Paper contributed for the 5th Conference of African Association of Agricultural Economists (AAAE), 23-26 September 2016, Addis Ababa, Ethiopia

Bethelhem, K. and Holden, S.2008. Difference in maize productivity between male and female headed households in Uganda. Ethiopian Development Research Institute ,Department of Economic and Resource Management, Norwegian University of life Sciences, Norway.

CSA (Central Statistics Agency).2015. Agricultural sample survey, report on area and production of crops. Addis Ababa, Ethiopia.

Davis, K., Swanson, B., Amudavi, D., Ayalew, D., Flohrs, A., Riese, J., and Zerfu, E. 2010. In-depth assessment of the public agricultural extension system of Ethiopia and recommendations for improvement (IFPRI Discussion Paper, 01041.

Doss, C. R., W. Mwangi, H. Verkuijl, and H. de Groote. 2003. Adoption of Maize and Wheat Technologies in Eastern Africa: A Synthesis of the Findings of 22 Case Studies. CIMMYT Economics Working Paper 0306. Mexico, D.F. CIMMYT.

Eneyew,T. 2013. Evaluation of Ethiopian Nigerseed (Guizotia Abyssinica Cass) Production, Seed Storage and Virgin Oil Expression. Landwirtschaftlich-Gärtnerische Fakultät der Humboldt-Universität zu Berlin. Pp 1, 9-16.

Fenta, M., Drost, S. and van Wijk, J. 2011. Multi-Stakeholder Platform Contribution to Value Chain Development. The Edible Oil and Oilseeds Value Chain in Ethiopia, Final Case Study Report. Pp 14-16.

Gotschi, E., J. Njuki, and R. Delve. 2008. Gender equity and social capital in smallholder farmer groups in 
central Mozambique, Development in Practice 18(4): 650-657.

Gujarati, D.N., 2004. Basic Econometrics: forth edition, Mac Graw-Hill, New York.

Gurumu, F., Mohammed, H., and Alemaw, G. 2009.Genotype X environment interactions and stability of soybean for grain yield and nutrition quality. Journal of African Crop Science, 17: 87-99.

Hutcheson, G. and Moutinho, L. 2008.Statistical Modeling for Management. Sage Publications. India, Pvt. Ltd. New Delhi 110044.

Muyanga, M., Jayne, T.S., and Bruke, W. J. 2011.Pathways into and out of Poverty: A Study of Rural Household Wealth Dynamics in Kenya. Paper presented at the Special IARIW-SSA Conference on Measuring National Income, Wealth, Poverty, and Inequality in African Countries; 28 September-1 October, Cape Town, South Africa.

Okpolu, P. and Victor, C.2015.Gender Production Efficiency among soybean Farmers in Gboko local Government Are of Benue state, Nigeri, International Journal of Agriculture Innovation and Research 4(2): $1319-1473$.

Regasa, C., Guush B., Fannaye T.and Alemayehu Seyoum Taffese.2012.Gender Differences in Access to Extension services and Agricultural productivity. Ethiopia strategy Support Program Working Paper 49, Ethiopia, IFPRI.

Sopov, M. and Yared S. (2015).Business Opportunities Report Soy \#9 in the series written for the Ethiopian Netherlands business event 5-6 November 2015, Rijswijk, the Netherlands.

Tadele M. and Mehendran, A. 2015.Gender Difference and Its Impact on Agricultural Production: The case of Sheko District in Bench Maji Zone of SNNP, Ethiopia. International Journal of Current Research, 7(11):22938-22942.

Tegebu, F.N., Mathijs, E., Deckers, J., Haile, M., Nyssen, J., and Tollens, E. 2012.Rural livestock asset portfolio in northern Ethipia: a microeconomic analysis of choice and accumulation. Tropical Animal Health and Production 44(1): 133-144.

Tewodaj, M., Cohen, M. J., Birner, R., Lemma, M., Randriamamonjy, J., Tadesse, F. and Paulos, Z. 2009. Agricultural extension in Ethiopia through a gender and governance lens. IFPRI: Washington D.C.

Udry, C., Hoddinott, J., Alderman, H. and Haddad, L.1995. 'Gender differentials in farm productivity: Implications for household efficiency and agricultural policy', Food Policy, 20(5): 407-423.

USDA, 2016.USDA assists in the development of Ethiopia's soy food industry. GAIN Report Number: ET1625

Villabon C. 2012. Gender Difference in Agricultural Productivity Across-sectional household survey data collected in 2006 in peru, MPh thesis Universitet I Oslo.

Wijnands, J.H.M, Biersteker J. and E. N.Van Loo, (2009). Oilseeds business opportunities in Ethiopia, Public Private Partnership on Oil (PPPO). Ministry of Agriculture, Nature and Food Quality, The Hage, The Netherlands. Pp10- 47.

Yemane, T.1967.Statistics; An Introductory Analysis, 2nd (ed).New York, Harper and Row publisher.

Yu, B., A. Nin-Pratt, J. Funes, and Asrat G. 2011. Cereal Production and Technology Adoption in Ethiopia. ESSP II Working Paper 31. Addis Ababa, Ethiopia: Ethiopia Strategy Support Program II, International Food Policy Research Institute. 